\title{
Analytical behaviour of concrete-encased CFST box stub columns under axial compression
}

\author{
J. Y. Chen ${ }^{a}$, L. H. Han ${ }^{a *}$, F. C. Wang ${ }^{a}$ and T. M. Mu ${ }^{b}$ \\ a Department of Civil Engineering, Tsinghua University, Beijing, China \\ ${ }^{b}$ Sichuan Province Transportation Department Highway Planning, Survey, Design and Research Institute, \\ Chengdu, China \\ *corresponding author, e-mail address: 1hhan@mail.tsinghua.edu.cn
}

\begin{abstract}
Concrete-encased CFST (concrete-filled steel tube) members have been widely used in high-rise buildings and bridge structures. In this paper, the axial performance of a typical concrete-encased CFST box member with inner CFST and outer reinforced concrete (RC) is investigated. A finite element analysis (FEA) model is established to analyze the compressive behavior of the composite member. The material nonlinearity and the interaction between concrete and steel tube are considered. A good agreement is achieved between the measured and predicted results in terms of the failure mode and the loaddeformation relation. The verified FEA model is then used to conduct the full range analysis on the load versus deformation relations. The loading distributions of different components inclouding concrete, steel tube and longitudinal bar during four stages are discussed. Typical failure modes, internal force distribution, stress development and the contact stress between concrete and steel tube are also presented. The parametric study on the compressive behavior is conducted to investigate the effects of various parameters, e.g. the strength of concrete and steel, longitudinal bar ratio and stirrup space on the sectional capacity and the ductility of the concrete-encased CSFT box member.
\end{abstract}

Keywords: Concrete-filled steel tube (CFST); concrete-encased; box member; compressive behavior; full-range analysis.

\section{Introduction}

Concrete-encased concrete-filled steel tube (CFST) is a steel-concrete composite member. Fig. 1(a) shows a schematic view of the cross section of this composite member, which consists of inner CFST component and outer reinforced concrete (RC) component. Compared to traditional steel columns and RC columns, the concrete-encased CFST columns have higher bearing capacity and better fire resistance due to the existence of outer concrete. Reinforced concrete (RC) box members have been widely used in bridges due to the large stiffness of bending and torsion [1]. As shown in Fig. 1(b), $\mathrm{RC}$ box columns generally have inner and outer stirrup to meet the requirements of ductility.

As shown in Fig. 1(c), the concrete-encased CFST box members are developed in order to take the advantages of concrete-encased CFST columns and RC box columns, which have
CFST component in the webs and corners of the RC box component. Fig. 1(d) shows a schematic view of an arch bridge with the concrete-encased CFST box arch ribs in Sichuan Province. The strength of core concrete is generally stronger than that of outer concrete.

Some previous research has been done on concrete-encased CFST columns (e.g. [2-4]) and $\mathrm{RC}$ box columns (e.g. $[1,5,6])$. An et al. [7] have analyzed the performance of concrete-encased CFST box column which only has CFST in the corners of the cross section. This paper establishes a finite element analysis (FEA) model of concrete-encased CFST box stub column under axial compression. After verified by the test results, the model is used to analysis the complete load-deformation curves and interactions between steel and concrete. A parametric study is also carried out for the influence of ultimate load and ductility. 


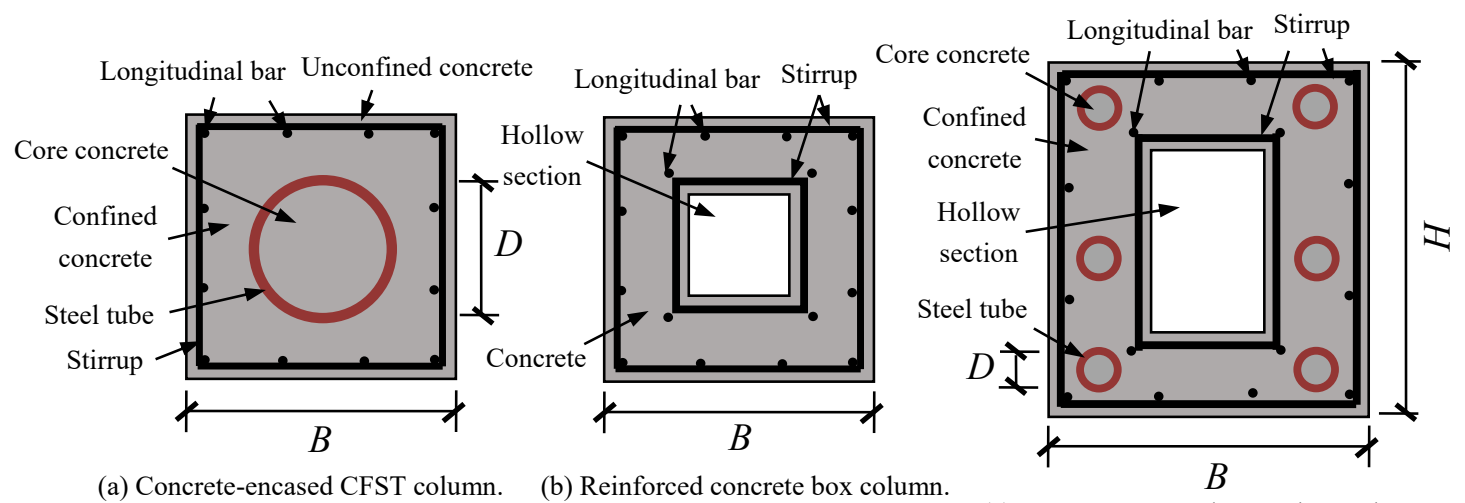

(a) Concrete-encased CFST column.

(b) Reinforced concrete box column

(c) Concrete-encased CFST box column.
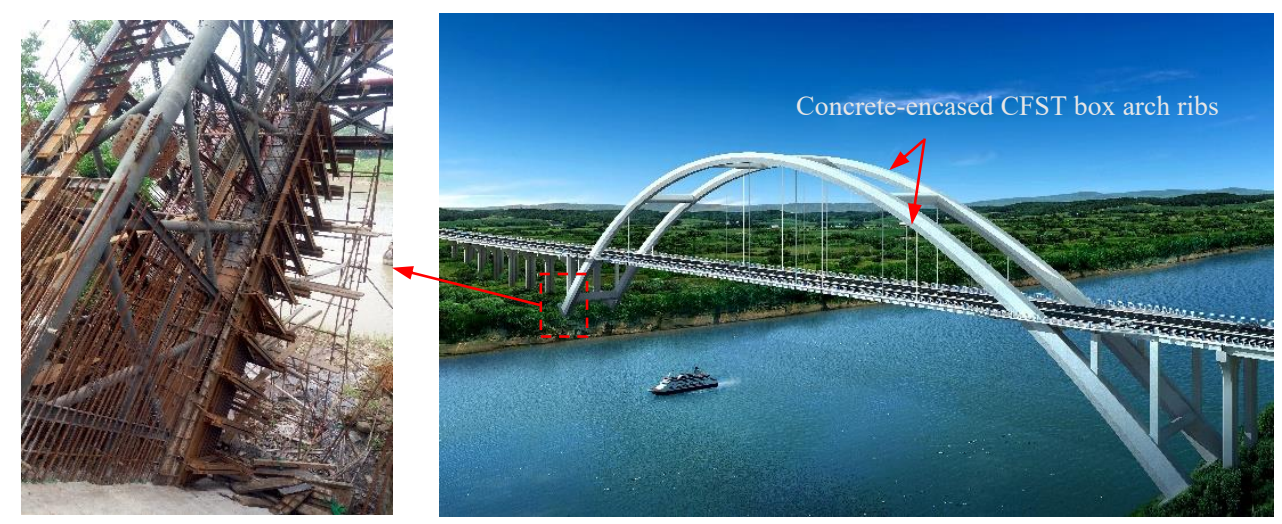

(d) A typical arch bridge with concrete-encased CFST box arch ribs in Sichuan Province.

Fig. 1. A schematic view of typical cross section.

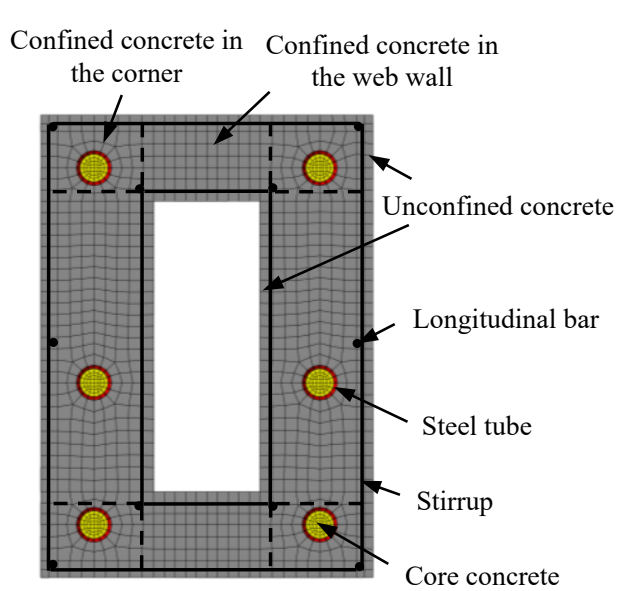

(a) Cross section.

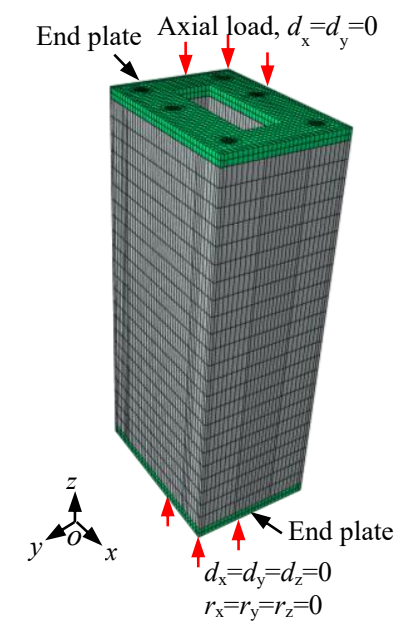

(b) Schematic view.

Fig. 2. Finite element model of concrete-encased CFST box stub column.

\section{Finite element analysis (FEA) model}

The ABAQUS/Standard module [8] is used to develop the FEA model of concrete-encased CFST box stub column under axial compression as shown in Fig. 2. The FEA model consists of steel tubes, concrete, longitudinal bars, stirrups and end plates. Considering the different confinement, the concrete can be divided as four regions: core concrete inside the steel tube, confined concrete in the corner, confined concrete in the web wall and unconfined concrete outside the stirrup.

\subsection{Material models}

\subsubsection{Steel}

Constitutive laws of steel tubes and bars are modeled through distinct non-linear material 
models. A five-stage stress-strain model suggested by Han et al. [9] is applied for steel tube. A bi-linear model considering strain hardening effect adopted by Zhao et al. [10] is used for the uniaxial stress-strain curves of the rebar. The elastic modulus and Poisson's ratio of the steel are consistently defined as 206,000 $\mathrm{N} / \mathrm{mm} 2$ and 0.3 , respectively.

\subsubsection{Concrete}

The damage plasticity model is utilized for the concrete. The elastic modulus of concrete is $4730 \sqrt{f_{c}^{\prime}}$ as presented in ACI 38-11 [11], in which $f_{c}^{\prime}$ represents the compressive strength of concrete cylinder. The Poisson's ratio of concrete is taken as 0.2 .

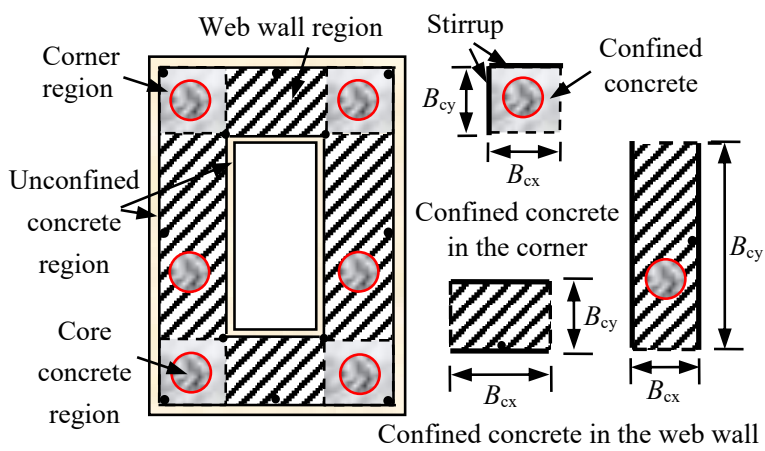

Fig. 3. A schematic view of concrete regions in the concrete-encased CFST box section.

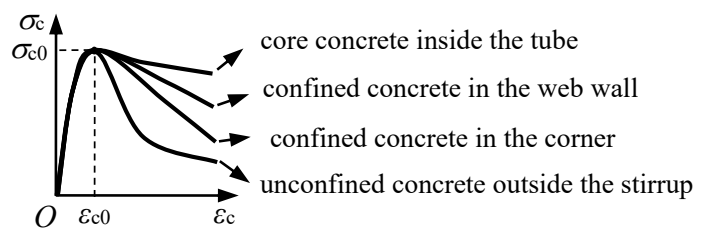

Fig. 4. Typical $\sigma_{\mathrm{c}}-\varepsilon_{\mathrm{c}}$ relation of concrete under compression.

As shown in Fig. 3, the concrete can be divided into four regions, namely core concrete inside the steel tube, confined concrete in the corner, confined concrete in the web wall and unconfined concrete outside the stirrup. Different stress-strain relations are applied depending on regions. For the core concrete in the tube, the model suggested by Han et al. [12] is adopted to represent the uniaxial stress-strain relation as shown in Fig. 4. A model of unconfined concrete provided by Attard and Setunge [13] is referred for the uniaxial stressstrain relation of unconfined concrete outside the stirrup. Fig. 4 also gives the stress-strain curves of the confined concrete in the corner and the web wall. Detailed description can be found in An et al. [7]. The length $B_{\mathrm{cx}}$ and $B_{\mathrm{cy}}$ are illustrated in Fig. 3.

For concrete in tension, the work done by Spacone et al. [14] is referred for the stress-strain relation of concrete in tension. The cracking strength of concrete $\sigma_{\mathrm{t}}$ is $0.3 \cdot\left(f_{c}^{\prime}\right)^{0.67}$ according to Model Code 2010 [15].

\subsection{Element type, mesh and boundary conditions and interface model}

Eight-node-3-D solid element with reduced integration is utilized for the concrete components and end plates. The steel tubes are simulated by four-node conventional shell element. However, eight-node-3-D solid element is adopted for steel tubes with the sizes of $\phi 12 \times 2 \mathrm{~mm}$ and $\phi 20 \times 2 \mathrm{~mm}$ because similar results are achieved when using either the solid element or the shell element [16]. The steel rebars are simulated by two-node truss elements.

Different mesh sizes are attempted to achieve the balance between accuracy and efficiency for calculation. The stiffness of end plates are assumed to be so large that the deformation can be neglected during the whole load stage. The load is simulated by applying displacement on one end plate along the column, while the displacement and rotation of the other end plate are restricted.

The rebar elements are embedded in the out concrete to restrict the degrees of freedom at the rebar node. In order to ensure the displacement and rotation of the interface remain consistent, "Tie" is utilized for the contact between steel tube and the end plate and the contact between concrete and the end plate. The contact between steel tube and concrete is simulated by the "Hard contact" model in the normal direction and the Mohr-Coulomb friction model in the tangential direction. Frictional coefficient of 0.6 suggested by Han and An [4] is used in this study.

\subsection{Verification}

Four concrete-encased CFST box stub columns tested by the authors are adopted to verify the FEA model above. Table 1 summarizes the geometric dimensions of all specimens. Fig. 5 shows the comparison of predicted and measured load $(N)$ versus longitudinal strain $(\varepsilon)$ relations. The mean value 
and the standard deviation of $N_{\mathrm{uc}} / N_{\text {ue }}$ (where $N_{\mathrm{uc}}$ and $N_{\text {ue }}$ are the calculated and measured ultimate loads, respectively) are 0.948 and 0.035 , respectively. It can be seen that a good agreement is achieved between the predicted and experimental results.

Table 1. Specimen information.

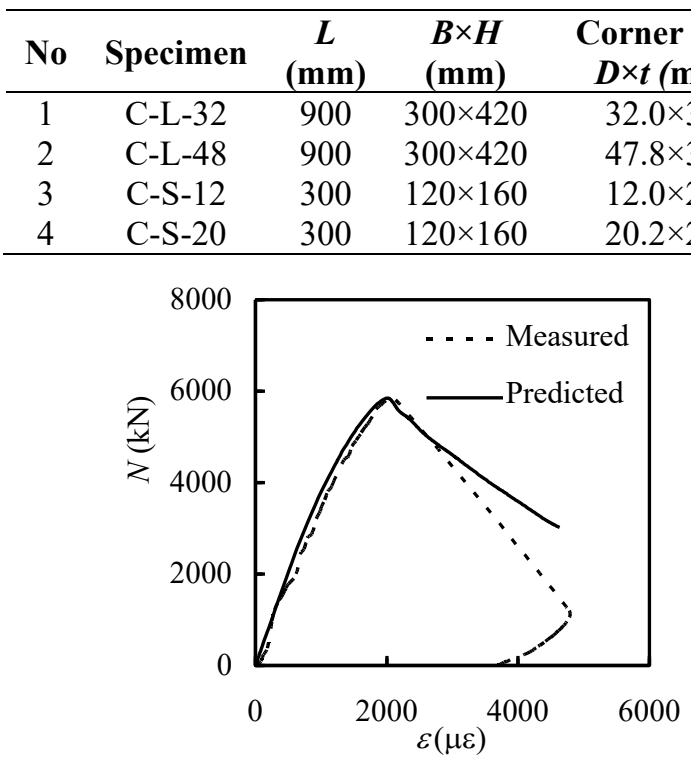

(a) C-L-32.

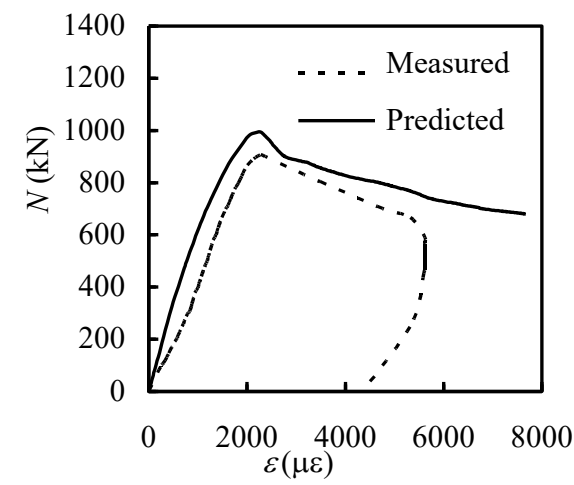

(c) C-S-12.

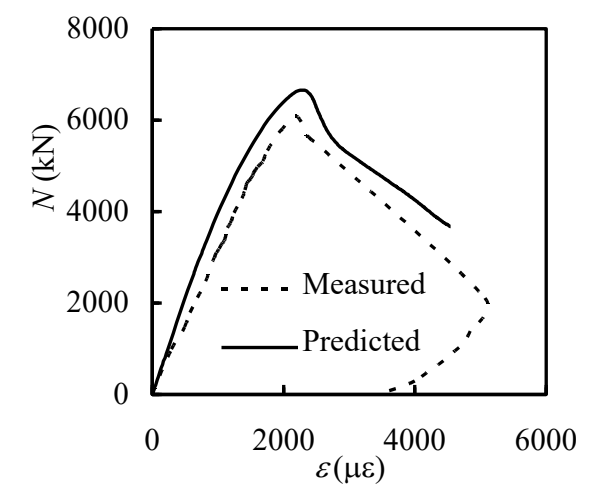

(b) C-L-48.

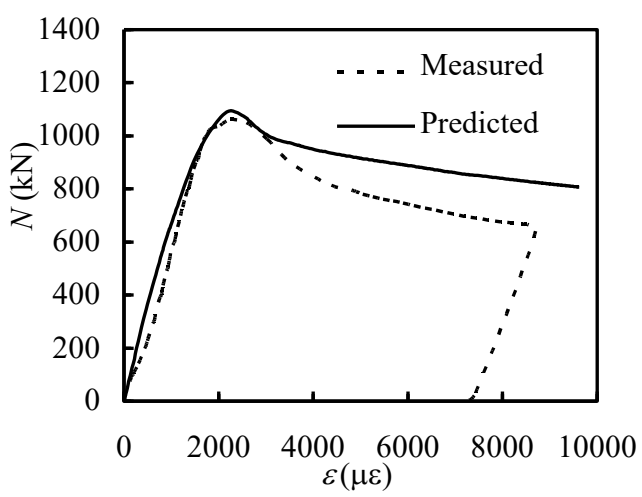

(d) C-S-20.

Fig. 5. Comparison of predicted and measured $\mathrm{N}-\varepsilon$ relations.

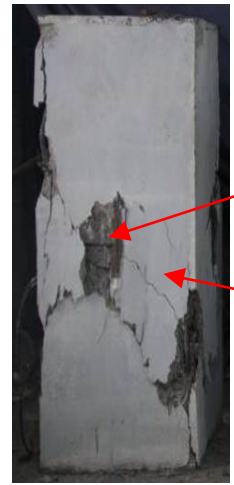

Observed

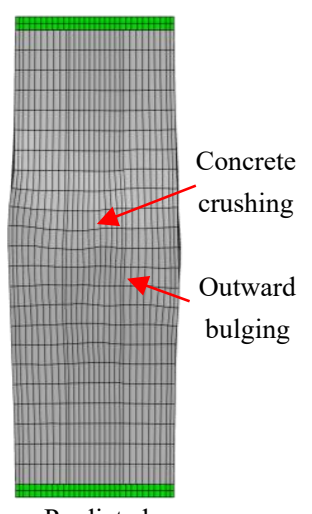

Predicted

(a) Outer concrete

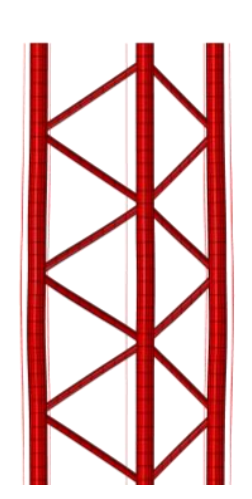

Predicted

(b) Inner steel component

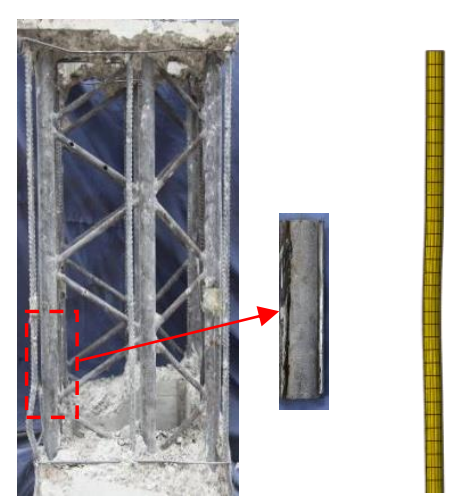

Observed

Observed Predicted

(c) Core concrete

Fig. 6. Comparison of failure modes between predicted and tested (specimen C-L-32). 
Typical failure modes from finite element simulations are compared with those from tests and the comparisons are presented in Fig. 6. It can be found that the outer concrete is crushed and bulged outward in the middle of the specimen. Bending deflection is observed in the inner CFST component, while the core concrete maintains intact due to the confinement of steel tube.

\section{Analytical behavior}

\subsection{Analysis of complete load-deformation curves}

A typical concrete-encased CFST box stub column with the section shown as Fig. 2(a) is designed to investigate the axial behavior. The sectional width $B$, height $H$ and length $L$ are 120 $\mathrm{mm}, 160 \mathrm{~mm}$ and $900 \mathrm{~mm}$, respectively. The width $B_{\mathrm{h}}$, and the height $H_{\mathrm{h}}$ of hollow section are $24 \mathrm{~mm}$ and $76 \mathrm{~mm}$, respectively. The diameter and the wall thickness of the steel tube $D$ are 12 $\mathrm{mm}$ and $2.1 \mathrm{~mm}$, respectively. The material properties are as follows: $f_{\text {cu,core }}=101 \mathrm{~N} / \mathrm{mm}^{2}$, $f_{\text {cu, out }}=59 \quad \mathrm{~N} / \mathrm{mm}^{2}, \quad f_{\mathrm{ys}}=527 \quad \mathrm{~N} / \mathrm{mm}^{2}, \quad f_{\mathrm{yl}}=383$ $\mathrm{N} / \mathrm{mm}^{2}$, longitudinal bar ratio $\alpha_{1}=1.1 \%$, diameter and space of stirrup are $4 \mathrm{~mm}$ and $50 \mathrm{~mm}$, respectively. The thickness of concrete cover is $5 \mathrm{~mm}$.

Fig. 7 gives the calculated axial load $(N)$ versus axial strain $(\varepsilon)$ relation of the concreteencased CFST box column. The $N-\varepsilon$ response of different components including core concrete of CFST, confined concrete, unconfined concrete, steel tube and longitudinal bar are also shown in the Fig. 7. Four characteristic points are marked in the curve. At point $\mathrm{A}$, the longitudinal bars begin yielding; at point $\mathrm{B}$, the unconfined concrete reaches the ultimate strength; at point $\mathrm{C}$, the column reaches the ultimate load $\left(N_{\mathrm{u}}\right)$; at point D, the load fails to $85 \%$ of $N_{\mathrm{u}}$.

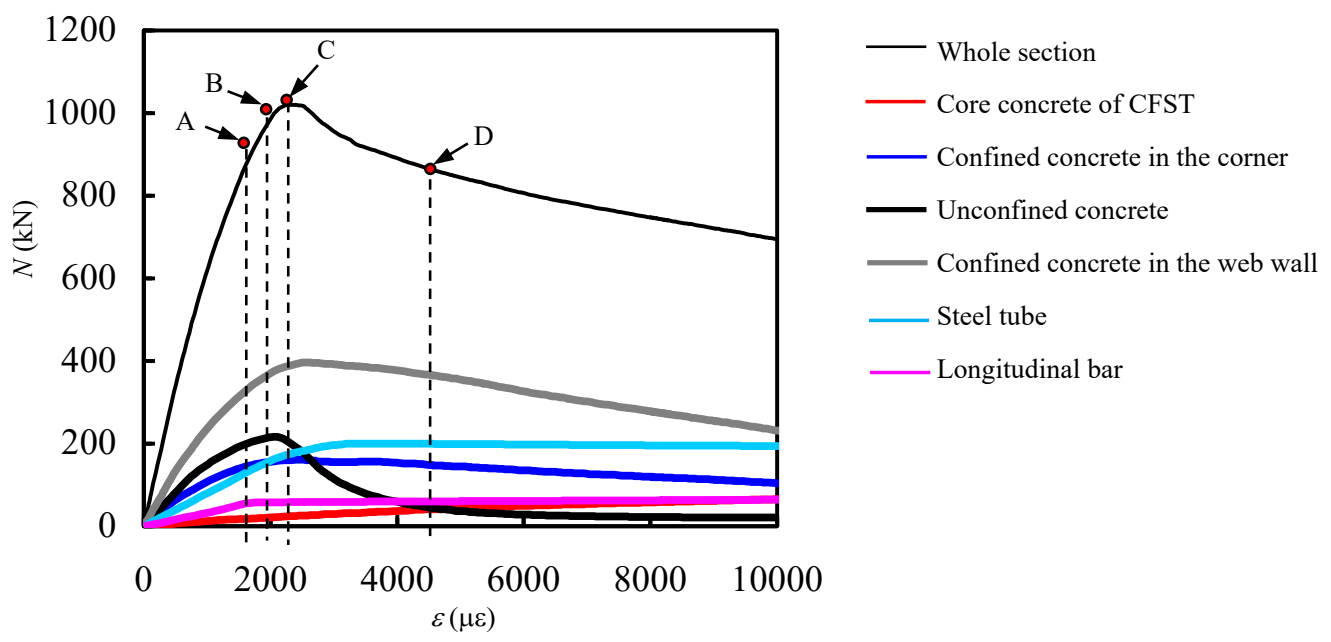

Fig. 7. Typical axial load $(N)$ versus axial strain $(\varepsilon)$ relation.

Stage I (OA). The column remains elastic behavior generally in this stage. The unconfined concrete, confined concrete in the web walls and confined concrete in the corners are sustaining $97 \%, 89 \%$ and $95 \%$ of their ultimate loads, respectively. The loads of core concrete and steel tube are $28 \%$ and $73 \%$ of its peak load, respectively.

Stage II $(\mathrm{AB})$. The longitudinal strain $(\varepsilon)$ increases faster when the axial load increases in this stage. The unconfined concrete reaches peak load at point B and begins to crush in the corner. The loads of core concrete inside steel tubes and confined concrete in the corners are $32 \%$ and $99 \%$ of their peak loads. The steel tubes are supporting $83 \%$ of its ultimate load. The longitudinal bars have yielded at point B.

Stage III (BC). During this stage, the load supported by unconfined concrete decreases, while the resistance sustained by the confined concrete in the web walls remains increasing.

Stage IV (CD). The whole load begins to fail and the longitudinal strain increases quickly. The loads supported by unconfined concrete and confined concrete in the corner begin to decrease, and the smallest stress occurs in the unconfined concrete outside the stirrups. The resistance of core concrete continues to increase slowly after point $\mathrm{C}$. 


\subsection{Interactions between steel and concrete}

The out concrete is confined by stirrup in the composite column. Fig. 8 shows the stirrup stress $\left(\sigma_{\mathrm{h}}\right)$ versus axial strain $(\varepsilon)$ relation at Point 1 in the middle of the column. With the increase of $\varepsilon$, $\sigma_{\mathrm{h}}$ is still in the elastic stage before Point A. The increasing trend of $\sigma_{\mathrm{h}}$ become more obvious after Point $\mathrm{A}$. The stirrup begins to yield at Point $\mathrm{C}$ when the $\mathrm{RC}$ component reaches the peak load.

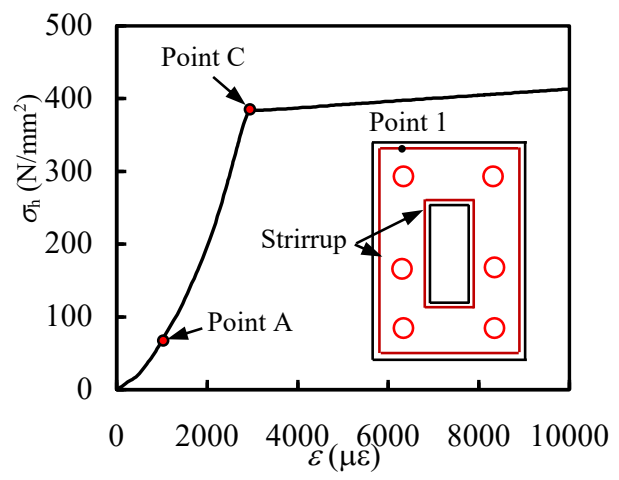

Fig. 8. Stress of stirrup $\left(\sigma_{\mathrm{h}}\right)$ versus axial strain $(\varepsilon)$ relation.

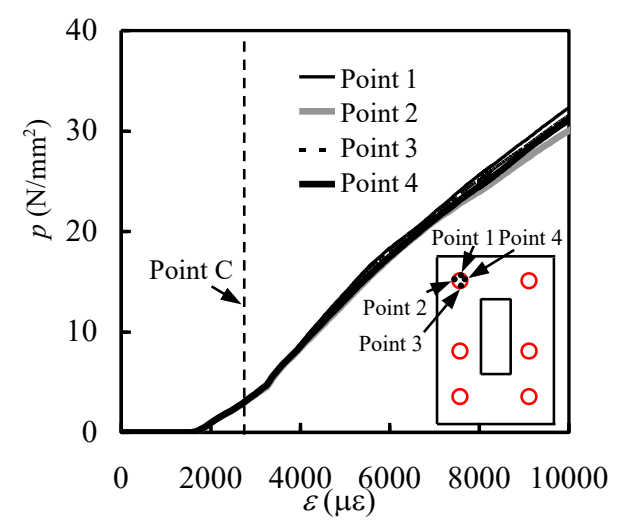

(a) $p_{1}$
The confinements to steel tubes are provided by both core concrete and encased concrete. Fig. 9 (a) shows the interaction stresses between steel tubes and core concrete $\left(p_{1}\right)$ while Fig. 9 (b) shows the interaction stresses between steel tubes and out concrete $\left(p_{2}\right)$. When $\varepsilon$ is less than $1600 \mu \varepsilon, p_{1}$ remains zero because the Poisson's ratio of steel tube is larger than that of core concrete in elastic stage and the lateral expansion of steel tube is larger than that of core concrete. When $\varepsilon$ is larger than $1600 \mu \varepsilon, p_{1}$ appears for the reason that the expansion of core concrete is larger than that of steel tube after concrete come into plastic stage. The longitudinal stress of core concrete is higher than that of unconfined concrete at Point $\mathrm{C}$ due to the existence of $p_{1}$. When $\varepsilon$ is smaller than $1600 \mu \varepsilon, p_{2}$ appears because the lateral expansion of steel tube is larger than that of out concrete. However $p_{2}$ is zero when $\varepsilon$ is larger than $1600 \mu \varepsilon$ because the lateral expansion of encased concrete is larger than that of steel tube. When $\varepsilon$ reaches $4000 \mu \varepsilon$, $p_{2}$ exists at Point 3 and Point 4 , which means the lateral deflection of steel tube is confined by out concrete.

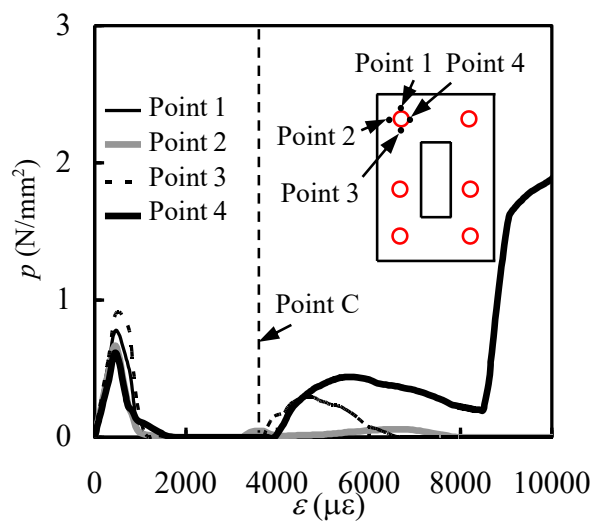

(b) $p_{2}$

Fig. 9. Interaction stresses between steel tubes and concrete.

\subsection{Parametric analysis}

The influence on the axial load $(N)$ versus the longitudinal strain $(\varepsilon)$ relation of various parameters is analyzed. The parameters are as follows: out concrete strength $f_{\text {cu,out }}=40-60$ $\mathrm{N} / \mathrm{mm}^{2}$, longitudinal bar ratio $\alpha_{1}=0.5 \%-1.5 \%$, yield stress of longitudinal bar $f_{\mathrm{yl}}=235$ $400 \mathrm{~N} / \mathrm{mm}^{2}$, space of stirrup $s=50-100 \mathrm{~mm}$, core concrete strength $f_{\text {cu,core }}=60-100 \mathrm{~N} / \mathrm{mm}^{2}$ and yield stress of steel tube $f_{\mathrm{ys}}=235-420 \mathrm{~N} / \mathrm{mm}^{2}$. Fig. 10 gives the effect of different parameters on $N-\varepsilon$ relations.

(1) Out concrete strength $\left(f_{\text {cu,out }}\right)$ : As shown in Fig. 10(a), the peak load $N_{\mathrm{u}}$ increases as $f_{\text {cu,out }}$ increases, but the ductility decreases due to the confinement provided by the stirrup.

(2) Longitudinal bar ratio $\left(\alpha_{1}\right)$ : It can be seen that $N_{\mathrm{u}}$ increases slightly as $\alpha_{\mathrm{l}}$ increases in Fig. 10(b). The effect of $\alpha_{1}$ on ductility is not 
significant because the confinement of stirrup is unchanged.

(3) Yield stress of longitudinal bar $\left(f_{\mathrm{yl}}\right)$ : Fig. 10(c) shows that $N_{\mathrm{u}}$ increases a little as $f_{\mathrm{yl}}$ increases. The influence of $f_{\mathrm{yl}}$ on ductility is not obvious due to the unchanged confinement of stirrup.

(4) Space of stirrup (s): As $s$ increases, $N_{\mathrm{u}}$ is not changed significantly and the ductility

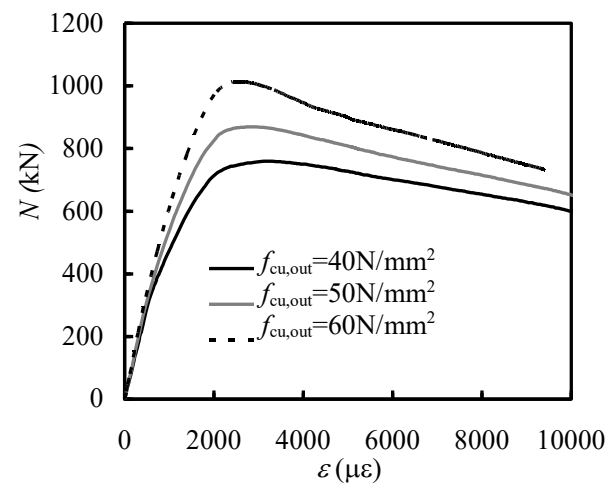

(a) $f_{\text {cu,out }}$

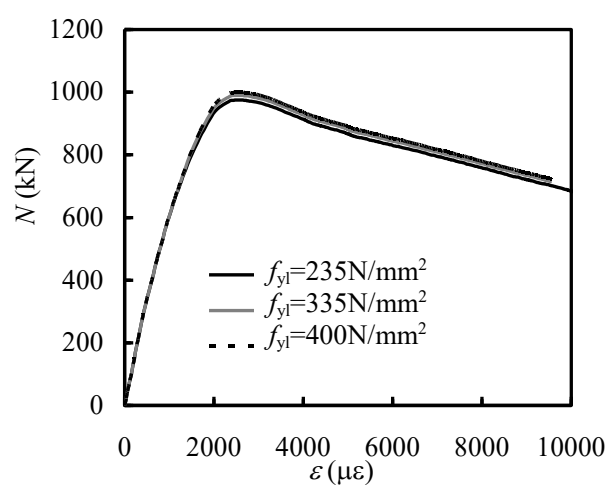

(c) $f_{\mathrm{yl}}$

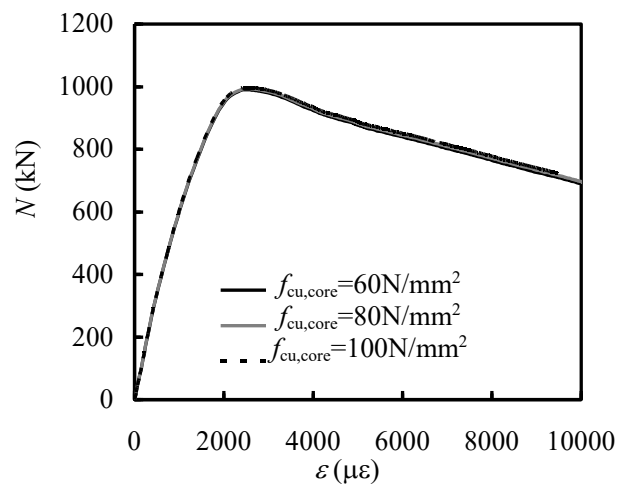

(e) $f_{\text {cu,core }}$ decreases because the confinement supported by the stirrup decreases.

(5) Core concrete strength $\left(f_{\text {cu,core }}\right)$ : As shown in Fig. 10(e), the ultimate load $N_{\mathrm{u}}$ increases a little as $f_{\text {cu,out }}$ increases for the reason that the load sustained by core concrete is not obvious.

(6) Yield stress of steel tube $\left(f_{\mathrm{ys}}\right)$ : Fig. 10(f) shows that $N_{\mathrm{u}}$ increases as $f_{\mathrm{ys}}$ increases because of the increase strength of the steel tube and CFST component.

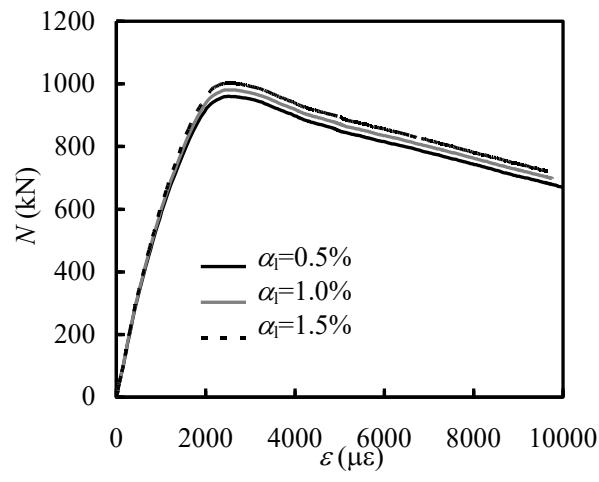

(b) $\alpha_{1}$

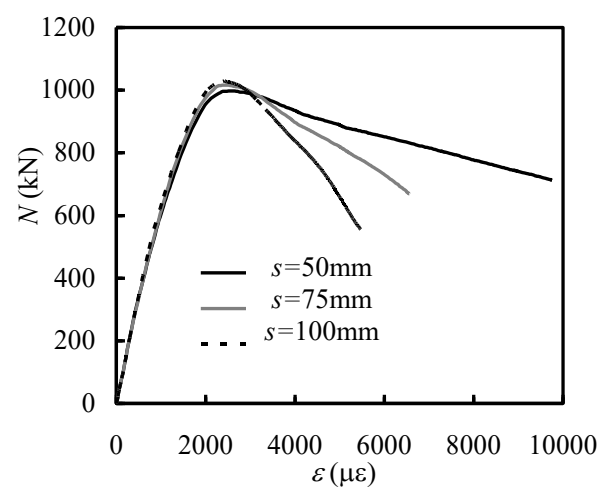

(d) $s$

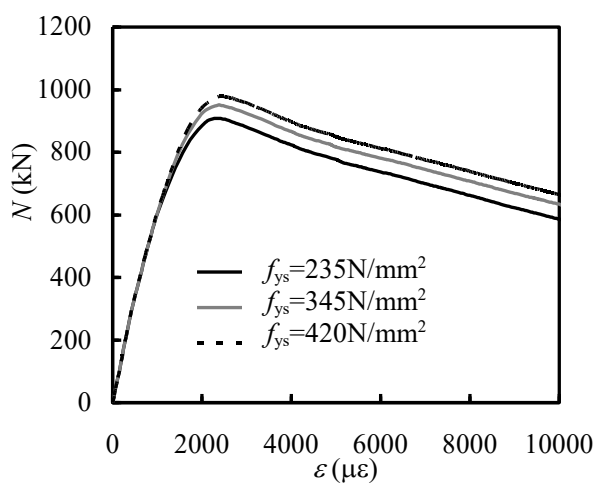

(f) $f_{\text {ys }}$

Fig. 10. Effects of different parameters on $N-\varepsilon$ relations. 


\section{Conclusions}

Based on the study in this paper, the following conclusions can be drawn:

(1) A FEA model of concrete-encased CFST box stub column under axial compression is established. Considering the difference of confinement, the concrete regions are divided as core concrete within the steel tube, confined concrete in the corner, confined concrete in the web wall and unconfined concrete outside the stirrup. A good agreement is achieved between the predicted and measured results.

(2) The axial load $(N)$ versus longitudinal strain $(\varepsilon)$ relation can be divided as four stages. The unconfined concrete outside the stirrup, confined concrete in the web wall and confined concrete in the corner reaches their ultimate loads while the axial load $N$ reaches $N_{\text {u}}$.

(3) The influence of different parameters on the peak load and ductility of the concreteencased CFST box stub column is discussed.

\section{References}

[1] Zhang YY, Harries KA, Yuan WC. Experimental and numerical investigation of the seismic performance of hollow rectangular bridge piers constructed with and without steel fiber reinforced concrete. Engineering Structures 2013; 48 :255-265.

[2] An YF, Han LH. Behaviour of concrete-encased CFST columns under combined compression and bending. Journal of Constructional Steel Research 2014; 101: 314-330.

[3] An YF, Han LH, Roeder C. Flexural performance of concrete-encased concrete-filled steel tubes. Magazine of Concrete Research 2014a; 66: 249-267.

[4] Han LH, An YF. Performance of concreteencased CFST stub columns under axial compression. Journal of Constructional Steel Research 2014; 93: 62-76.

[5] Papanikolaou VK, Kappos AJ. Numerical study of confinement effectiveness in solid and hollow reinforced concrete bridge piers: Analysis results and discussion. Computers and Structures 2009; 87: 1440-1450.

[6] Zahn FA, Park R, Priestley MJN. Flexural strength and ductility of circular hollow reinforced concrete columns without confinement on inside face. Structural Journal 1990; 87: 156-166.
[7] An YF, Han LH, Roeder C. Performance of concrete-encased CFST box stub columns under axial compression. Structures 2015; 3: 211-226.

[8] Hibbitt, Karlson, Sorenson Inc. ABAQUS Version 6.5: theory manual, users' manual, verification manual and example problems manual; 2005.

[9] Han LH, Zhao XL, Tao Z. Tests and mechanics model for concrete-filled SHS stub columns, columns and beam-columns. Steel and Composite Structures 2001; 1: 51-74.

[10]Zhao XM, Wu YF, Leung AYT. Analysis of plastic hinge regions in reinforced concrete beams under monotonic loading. Engineering Structures 2012; 34: 466-482.

[11]ACI 318-11. Building code requirements for structural concrete and commentary. Detroit (USA): American Concrete Institute; 2011.

[12] Han LH, Yao GH, Tao Z. Performance of concrete-filled thin-walled steel tubes under pure torsion. Thin-Walled Structures 2007; 45: 24-36.

[13] Attard MM, Setunge S. Stress-strain relationship of confined and unconfined concrete. ACI Materials Journal 1996; 93: 432-442.

[14] Spacone E, Filippou F, Taucer F. Fibre beamcolumn modeling for nonlinear analysis of $\mathrm{R} / \mathrm{C}$ frames. Part I: formulation. Earthquake Engineering and Structural Dynamics 1996; 25: 711-725.

[15] Fédération Internationale du Béton. Model code 2010: first complete draft. Switzerland: Lausanne; 2010.

[16] Dai XH, Lam D, Jamaluddin N, Ye J. Numerical analysis of slender elliptical concrete filled columns under axial compression. Thin-Walled Structures 2014; 77: 26-35. 